\title{
Increase in the yield of silicon carbide whiskers from rice husk
}

\author{
B V RADHAKRISHNA BHAT and G P SANGHI* \\ Defence Metallurgical Research Laboratory, Kanchanbagh, Hyderabad 500258 , India \\ *Present address: Defence Research and Development Laboratory, Hyderabad 500258 , \\ India \\ MS received 18 May 1987; revised 7 July 1987
}

\begin{abstract}
Favourable conditions for the growth of good quality silicon carbide (SiC) whiskers from rice husk have been discussed in the light of available evidence on the probable growth mechanism and the theoretical understanding of the same. Preliminary results indicate an increase in whisker yield at lower temperatures and coarsening of whiskers with longer duration of conversion.
\end{abstract}

Keywords. Silicon carbide whiskers; rice husk: vapour-liquid-solid process.

\section{Introduction}

Silicon carbide whiskers have emerged as an attractive reinforcement in both metal and ceramic matrix composites. Silicon carbide whisker-reinforced aluminium is the topic of many recent research papers (Nair et al 1985; Flom and Arsenault 1986; David 1985; Vogelsang et al 1986) after the original one by Divecha et al (1981) and is reported to be a strategic material. Silicon carbide whiskers have been reported to be useful in enhancing the strength, fracture toughness and reliability of ceramic matrix composites (Sudarshan and Musikant 1985; Tiegs and Bacher 1986). All this has become possible due to the development of processes to produce silicon carbide whiskers on a commercial scale. Table 1 gives the properties of these whiskers as reported in literature (Sudarshan and Musikant 1985).

Milewski et al (1985) listed various methods that have been reported to be useful in producing $\mathrm{SiC}$ whiskers. One of them is the process developed by Lee and Cutler (1975) in the University of Utah wherein it was demonstrated that $\mathrm{SiC}$ may be produced by the pyrolysis of rice husk yielding part of the product in the form of whiskers. Although various authors (Milewski et al 1973; Lakiza and Dyban 1982) have described this process, the optimum parameters for a higher yield of whiskers in the product are not mentioned in the literature probably due to the commercial interests involved. In this paper, an attempt has been made to discuss the probable whisker growth mechanism and the favourable conditions for enhancing the yield of whiskers in the light of available evidence and the theoretical understanding of the process. Preliminary work has in fact proved the validity of some of the suggested favourable conditions.

\section{Process}

Rice husk, a waste product of rice milling, is an ideal raw material for silicon carbide production, since in natural form it contains amorphous silica and carbon in a finely inixed form. The typical composition of rice husk and its ash (Bechtold et al 1982) is 
Table 1. Properties of commercially available SiC whiskers.

\begin{tabular}{lcccccc}
\hline Material & Manufacturer & $\begin{array}{c}\text { Density } \\
(\mathrm{g} / \mathrm{cc})\end{array}$ & $\begin{array}{c}\text { Diameter } \\
(\mu \mathrm{m})\end{array}$ & $\begin{array}{c}\text { Length } \\
(\mu \mathrm{m})\end{array}$ & $\begin{array}{c}\text { Tensile } \\
\text { strength } \\
(\mathrm{MPa})\end{array}$ & $\begin{array}{c}\text { Tensile } \\
\text { modulus } \\
(\mathrm{GPa})\end{array}$ \\
\hline $\begin{array}{l}\text { SILAR } \\
\text { SC-9 }\end{array}$ & $\begin{array}{c}\text { ARCO Metals } \\
\text { Greer. SC USA }\end{array}$ & $3 \cdot 20$ & 0.6 & $\begin{array}{c}10-80 \\
(80 \mathrm{wt} \%)\end{array}$ & 6895 & 689 \\
SCW-1 & $\begin{array}{c}\text { Tateho Chemical } \\
\text { Ind. Co., Japan }\end{array}$ & 3.21 & $0 \cdot 1-0.5$ & $10-40$ & 20685 & 483 \\
& & & & & \\
\hline
\end{tabular}

Table 2. Typical composition of rice husk and its ash.

\begin{tabular}{ll}
\hline Compound & Weight $(\%)$ \\
\hline Raw rice husk analysis & \\
Organics & $59 \cdot 5$ \\
Carbon & $18 \cdot 8$ \\
Ash & $20 \cdot 6-21 \cdot 7$ \\
Ash residue analysis & \\
$\mathrm{SiO}_{2}$ & $96 \cdot 27$ \\
$\mathrm{~K}_{2} \mathrm{O}$ & $1 \cdot 10$ \\
$\mathrm{SO}_{3}$ & 0.57 \\
$\mathrm{P}_{2} \mathrm{O}_{5}$ & 0.39 \\
$\mathrm{MgO}$ & $0 \cdot 35$ \\
$\mathrm{Na}_{2} \mathrm{O}$ & $0 \cdot 25$ \\
$\mathrm{Fe}_{2} \mathrm{O}$ & $0 \cdot 10$ \\
$\mathrm{Al}_{2} \mathrm{O}$ & $0 \cdot 10$ \\
$\mathrm{TiO}_{2}$ & 0.08 \\
\hline
\end{tabular}

given in table 2. The main steps involved in the formation of silicon carbide from rice husk are shown in figure 1.

The reaction steps have been discussed in detail earlier (Lee and Cutler 1975; Bechtold et al 1982). The silicon carbide formation occurs by the reaction

$$
\mathrm{SiO}_{2}+3 \mathrm{C} \rightarrow \mathrm{SiC}+2 \mathrm{CO},
$$

where excess carbon is available. But, due to the uneven distribution of silica within the rice husk (Sharma et al 1984; Bechtold et al 1982) it may proceed through any of the following steps:

$$
\begin{aligned}
& \mathrm{SiO}_{2}+\mathrm{C} \rightarrow \mathrm{SiO}+\mathrm{CO}, \\
& \mathrm{SiO}+2 \mathrm{C} \rightarrow \mathrm{SiC}+\mathrm{CO}, \\
& \mathrm{SiO}+3 \mathrm{CO} \rightarrow \mathrm{SiC}+2 \mathrm{CO}_{2}, \\
& \mathrm{SiO}+\mathrm{CO} \rightarrow \mathrm{SiC}+\mathrm{O}_{2} .
\end{aligned}
$$

Lee and Cutler (1975) suggested that the reaction proceeds mainly via the gas phase and the rate-controlling step is the carbothermal reduction of silica to form $\mathrm{SiO}$ and $\mathrm{CO}$ (equation (2)). Bechtold et al (1982) concluded that the excess carbon in the interior cell-walls leads to the formation of silicon carbide particulates by the solid state reaction (1) above, while the silicon carbide whiskers grow on the outer cellwalls by the vapour phase reactions (2), (3), (4) and (5). 


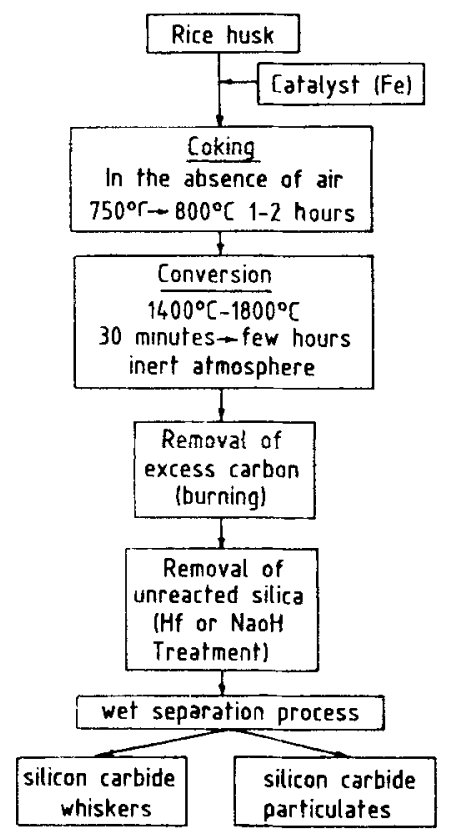

Figure 1. Steps in the formation of silicon carbide whiskers from rice husk.

\section{Evidence for the probable growth mechanism}

There are two important mechanisms of whisker growth from vapour phase, namely the Frank mechanism and the vapour-liquid-solid (VLS) mechanism (Evans 1972). The former suggests that whiskers contain one or more screw dislocations parallel to their growth axes and the steps or ledges due to the dislocations at the whisker tips provide the energetically-favoured sites for growth to continue. The latter postulates that the presence of small liquid droplet acts as a preferred site for whisker growth at the tip of each whisker.

Observations by various authors in regard to silicon carbide formation from rice husk (Lee and Cutler 1975; Lakiza and Dyban Yu 1982; Bechtold et al 1982) and the studies concerning the structure of whiskers produced from rice husk (Nutt 1984; Sharma et al 1984) have provided an insight into the most probable growth mechanism operating in this process.

Nutt (1984) discussed the various types of defects found in the silicon carbide whiskers grown from rice husk. Frank mechanism was ruled out due to the absence of axial screw dislocations in any of the whiskers. The abundance of cavities observed in the core regions of these whiskers points to the possibility of a two-stage growth process in which a whisker grows rapidly in length by the VLS mechanism followed by a slower lateral growth by some other mechanism. The cavities could arise from the entrapment of carbon monoxide gas evolved during the rapid growth period. Subsequent lateral growth at slower rates might account for the absence of cavities outside the whisker core region. The radial partial dislocations associated with the cavities are attributed to the nucleation of faulted regions near the whisker core, followed by crystal growth in radial directions. Sharma et al (1984) also 
observed a similar high density of planar defects and hollow whiskers, concluding that their work provides limited support to the VLS mechanism as spheres were sometimes found on the whisker tips.

It was concluded by earlier workers (Lee and Cutler 1975; Bechtold et al 1982; Lakiza and Dyban Yu 1982) that the whisker growth occurs from the vapour phase while Lakiza and Dyban $Y_{u}$ (1982) confirm the presence of spheroidal whisker tips suggesting a VLS mechanism of whisker growth. Although Lee and Cutler (1975) have not mentioned about the whisker growth mechanism, the photograph of whiskers presented by them clearly shows whiskers ending with spherical tips. Hence, various evidences mentioned above largely suggest VLS mechanism, combined with possibly other less important mechanisms depending upon changing parameters. A better understanding of the VLS mechanism is therefore expected to give a higher yield of whiskers. Evans (1972) gave a detailed analysis of the VLS mechanism and outlined the parameters essential for this growth mechanism to operate while Milewski et al (1985) and George and John (1985) described a VLS process of growing silicon carbide whiskers.

\section{Suggested conditions for favourable growth}

Whisker growth from vapour phase is essentially a preferential nucleation and preferential growth process. To increase whisker yield, both nucleation and growth must be controlled. The thermodynamics, kinetics, temperature, gas flow rates, availability and concentration of growth species, $\mathrm{Si} / \mathrm{C}$ ratio and a free space to grow are some of the important considerations.

\subsection{Temperature}

To control nucleation, i.e. to promote heterogeneous nucleation and to avoid homogeneous nucleation, it is necessary to control supersaturation and provide preferential nucleation sites. Higher supersaturations lead to spontaneous homogeneous nucleation and higher temperatures will lead to higher supersaturations. A temperature slightly above the equilibrium temperature of the reaction responsible for $\mathrm{SiC}$ formation must therefore help in avoiding homogeneous nucleation. An increase in temperature, apart from increasing the supersaturation level, usually reduces the contact angle between the alloy droplet and the substrate and eventually a smooth film growth can result (Evans 1972). Lakiza and Dyban Yu (1982) also suggested lower temperatures for a different reason. They believe that higher temperatures favour the formation of crystalline $\mathrm{SiO}_{2}$ and silicates which are more stable and less reactive thus effectively hindering $\mathrm{SiC}$ formation.

\subsection{Atmosphere}

Bechtold et al (1982) discussed the inert atmosphere to be used for the conversion. Argon is the inert gas used in their process for conversion. Nitrogen can be used, but at lower temperatures it has the tendency to react to form silicon nitride. Carbon monoxide can also be used but large concentrations can inhibit the reaction as it is a product of reaction nos. (1), (2) and (3). Hydrogen can also be used, but offers no real 
advantage even though it might help to increase the SiO concentration by the reaction

$$
\mathrm{SiO}_{2}+\mathrm{H}_{2} \rightarrow \mathrm{SiO}+\mathrm{H}_{2} \mathrm{O} \text {. }
$$

Vacuum will be unfavourable to whisker growth as it will remove the vapours containing the whisker growth species. Being a vapour phase reaction, even the flow rates of the inert or reducing gases supplied through the sample must be kept low to prevent sweeping the gaseous reactants away from the growth site. Fast moving gases can also destabilize the liquid droplet at the whisker tip and hinder whisker growth. The composition of the gases must be adjusted so as to provide a correct $\mathrm{Si} / \mathrm{C}$ ratio for whisker growth.

\subsection{Catalyst}

A catalyst must be selected so as to form an alloy droplet at the conversion temperature with the reacting species and must have the correct distribution coefficient between the liquid and the solid whisker. It must also have a low vapour pressure at the growth temperature. Lee and Cutler (1975) used Fe as a catalyst, while Milewski et al (1985) mention 304 stainless steel as the catalyst. George and John (1985) tried a Mn-Ni-Co alloy as the catalyst.

\subsection{Conversion chamber design}

A proper growth chamber is essential to ensure (i) a substrate for the whiskers to nucleate, (ii) a free space for the whiskers to grow and (iii) a system to introduce the inert gases without disturbing the growing whiskers. Milewski et al (1985) and George and John (1985) described a growth chamber for their VLS process. We suggest an improved version of the same as depicted in figure 2, wherein the growth substrate plates have been made horizontal and the $\mathrm{SiO}$ generators have been kept on the sides. The horizontal plates are expected to give better stability for the liquid droplet on the whisker tips apart from providing a surface for uniform distribution of catalyst and sufficient free space for the whiskers to grow. Finely ground coked rice husk can be substituted for the fine mixture of $\mathrm{SiO}_{2}$ and carbon (Milewski et al 1985)

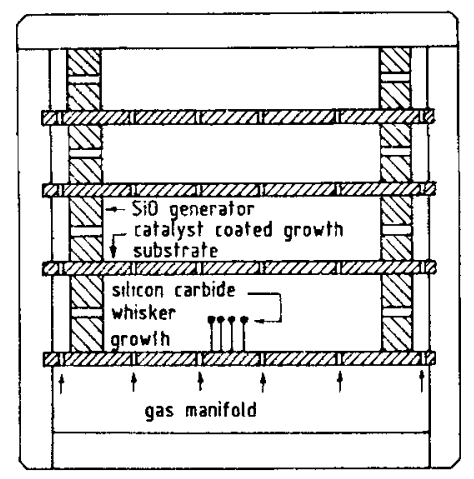

rigure 2. Whisker grow th chamber design. 
and impregnated into the porous bricks acting as $\mathrm{SiO}$ generators. The holes provided in the substrate plates and the $\mathrm{SiO}$ generators will help in the proper distribution of the gases prevailing within the chamber.

\subsection{Duration at high temperature}

Since whisker growth rates can be as high as a few $\mathrm{mm} / \mathrm{sec}$, the duration must be just sufficient for the whiskers to grow to their full lengths between the substrate plates. A duration longer than what is necessary will only lead to coarsening of the whiskers and also secondary whisker growth may occur leading to interlocking which is not desirable. It is also essential to keep the temperature constant throughout the whisker growth duration as any fluctuation can give rise to complications in terms of droplet stability, whisker diameter variation etc.

\section{Experimental results}

Preliminary studies were carried out to assess the feasibility of producing silicon carbide whiskers from rice husk. Rice husk obtained from local sources was dried and treated by soaking it in $3 \mathrm{wt} \% \mathrm{FeSO}_{4}$ solution at $75^{\circ} \mathrm{C}$ for $1 \mathrm{hr}$. $\mathrm{FeSO}_{4}$ was then drained out and the husk was then soaked in $10 \mathrm{wt} \% \mathrm{NH}_{3}$ solution for $1 \mathrm{hr}$ at room temperature. After soaking the husk was washed with water and dried at $110^{\circ} \mathrm{C}$ for $5 \mathrm{hr}$. This was then coked at $700^{\circ} \mathrm{C}$ for $30 \mathrm{~min}$. Oxidation was prevented by covering the layer of rice husk with a thin layer of petroleum coke. The weight loss due to coking was $55 \%$.

Coaked rice husk was heat-treated in two batches of $200 \mathrm{~g}$ each in a $\mathbf{H}_{2}$ atmosphere furnace. One of them was treated at $1600^{\circ} \mathrm{C}$ for $30 \mathrm{~min}$ while the other was treated at $1500^{\circ} \mathrm{C}$ for $2 \mathrm{hr}$. The heat-treated samples were purified by burning off the excess carbon and leaching out the unreacted $\mathrm{SiO}_{2}$ by boiling in $\mathrm{NaOH}$ solution. The filtered and dried product was analysed by $X$-ray diffraction. Samples of coked rice husk and the final product were also studied by SEM. X-ray diffraction data confirmed that the product was silicon carbide of the $\beta$ polytype.

SEM analysis showed that the coked rice husk maintains its skeletal structure (figure 3 ) and that the final product is a mixture of submicron size silicon carbide particulates and whiskers. While the whisker content is very less (figure 4) in the sample treated at higher temperature there is a visible increase in the content of whiskers in the lower temperature treated sample (figure 5). Comparison of figures 4 and 5 reveals coarsening of whiskers in the longer duration treated sample. There is a frequent change in diameter and growth direction of whiskers in the longer duration treated sample, possibly due to fluctuations in temperature and the non-availability of free space for the whiskers to grow straight.

\section{Conclusion}

Experimental evidence and observations of the various authors available in literature suggest VLS mechanism to be the most probable mechanism operating in the growth of silicon carbide whiskers from rice husk. Even if VLS mechanism is not the only operating mechanism, it is felt that by promoting favourable conditions for the VLS 


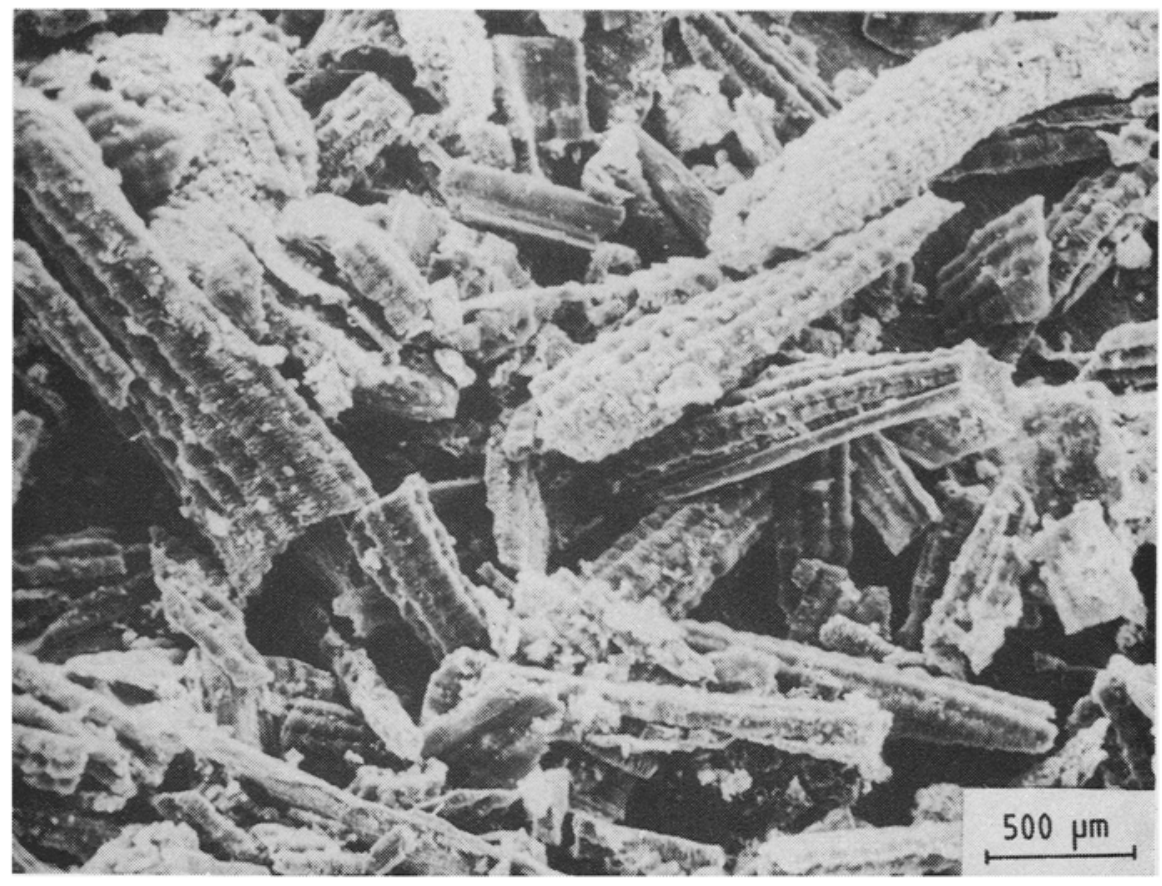

Figure 3. Scanning electron micrograph of coked rice husk.

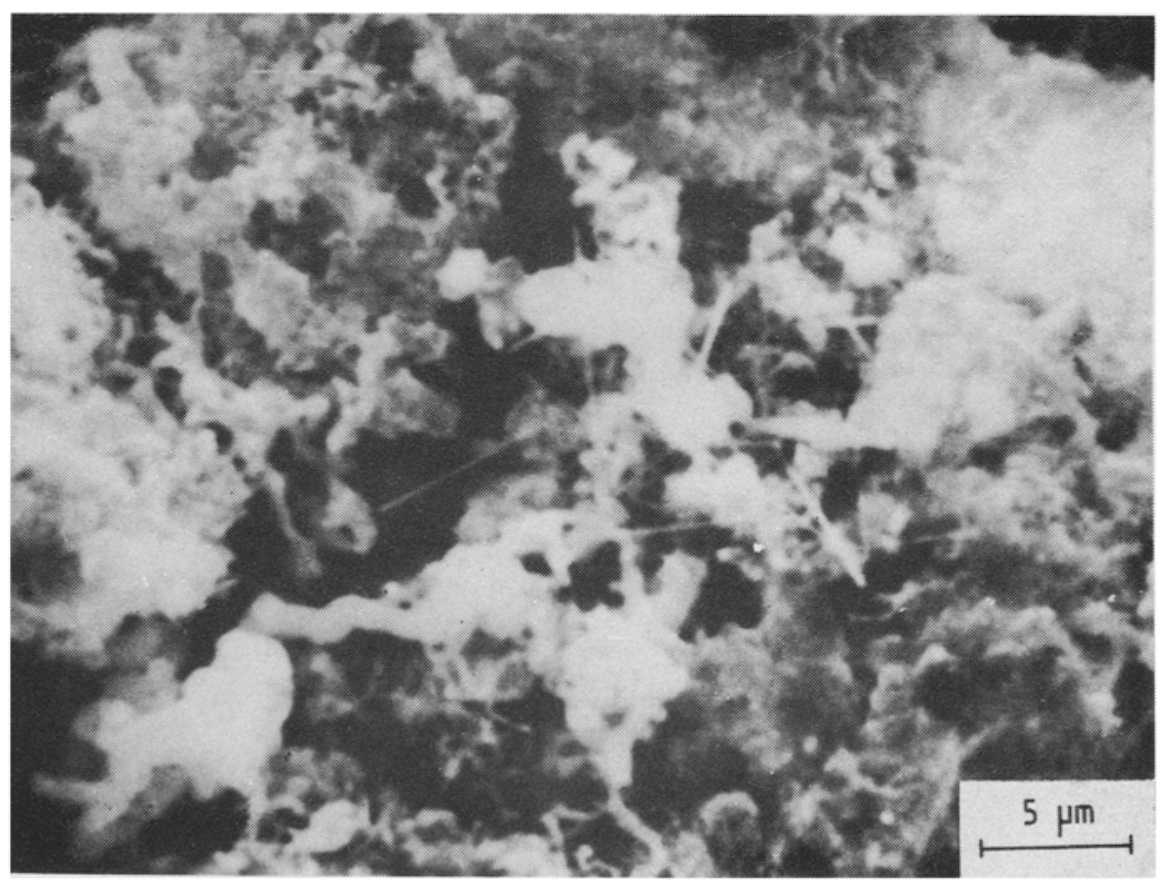

Figure 4. Scanmeng electron merograph of silicon carbide formed at $1600 \mathrm{C}(30 \mathrm{~min}$ duration). 


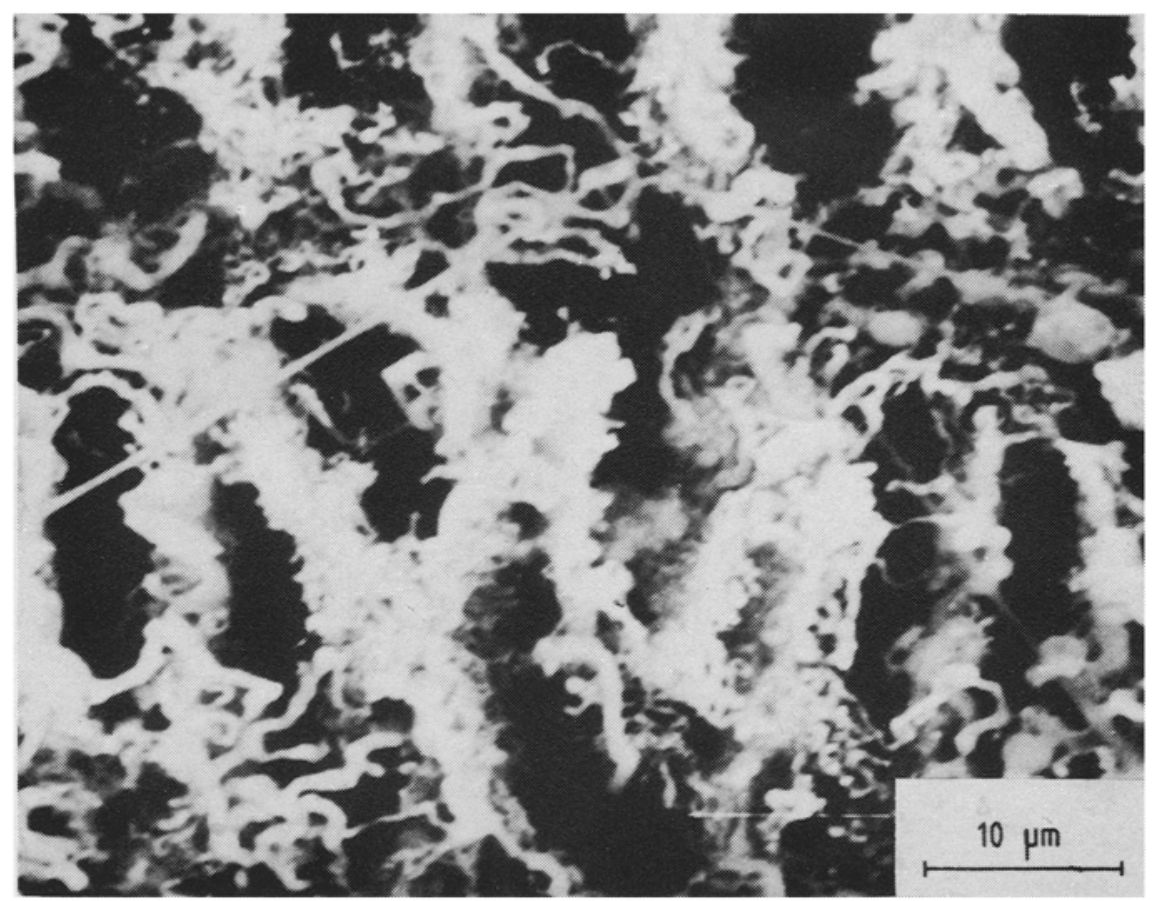

Figure 5. Scanning electron micrograph of silicon carbide formed at $1500^{\circ} \mathrm{C}(2 \mathrm{hr}$ duration).

mechanism, it will, however, be possible to increase the yield of good quality silicon carbide whiskers from rice husk. Preliminary experimental work confirms some of these ideas.

\section{Acknowledgements}

The authors are grateful to Dr P Rama Rao for encouragement. Experimental assistance of Mr P Balakrishna, (Nuclear Fuel Complex, Hyderabad), Mr Y V Rama Krishna and $\mathrm{Mr} \mathrm{K}$ Ramanjaneyulu is gratefully acknowledged.

\section{References}

Bechtold B C, Beatly R L and Cook J L 1982 Progress in science and engineering of composites (eds) Tsuyoshi Hayashi, Kozo Kawata and Sokichi Umakawa; (Tokyo: The Japan Society for Composite Materials) p. 113-120

David M L 1985 Metall. Trans. A16 1105

Divecha A P. Fishman S G and Karmarkar S D 1981 J. Met. 3312

Evans C C $1972 M$ and B monograph ME/8 whiskers (ed) J Gordon Cook (London: Mills and Boon Ltd) Chapt. 1, 2 and 3

Flom $Y$ and Arsenault R J $1986 J$. Mtt. 3831

George Hurly F and John Petrovic J 1985 Adranced composites conference proceedings (Michigan: American Society for Metals\} p. 207-212 Lakiza S N and Dyban Yu P 1982 Sot. Powder Met. Met. Ceram. 21117 Lee J G and Cutler I B 1975 Ceram. Bull. 2195 
Vogelsang M, Arsenault R J and Fisher R M 1986 Metull. Trans. A17 379

Milewski J V, Gac F D, Petrovic J J and Skaggs S R 1985 J. Mater. Sci. 201160

Milewski J V, Sandstrom J C and Brown W S 1973 Silicon carbide (eds) R C Marshall, J W Faust Jr and C E Ryan (Columbia: University of South Carolina Press) p. 634

Nair S V, Tien J K and Bates R C 1985 Int. Met. Rev. 30275

Nutt S R 1984 J. Am. Ceram. Soc. 67428

Sharma N K, Wendell W S and Zangwill A 1984 J. Am. Ceram. Soc. 67715

Sudarshan S C and Soloman M 1985 Ceram. Eng. Sci. Proc. 6663

Tiegs T N and Bacher P F 1986 Ceram. Eng. Sci. Proc. 71182 